\title{
Assessment of Drought in Sabarkantha District Using Reconnaissance Drought Index (RDI)
}

\author{
Nikhil A. Lunagaria ${ }^{1}$, T. M. V. Suryanarayana ${ }^{2}$ \\ ${ }^{1}$ P.G. Student, Water Resources Engineering and Management Institute, Faculty of Technology \& Engineering, \\ The Maharaja Sayajirao University of Baroda, Gujarat, India \\ ${ }^{2}$ Associate Professor, Water Resources Engineering and Management Institute, Faculty of Technology Engineering, The Maharaja \\ Sayajirao University of Baroda, Gujarat, India
}

\begin{abstract}
A drought is a period of below-average precipitation in a given region, resulting in prolonged shortages in its water supply, whether atmospheric, surface water or ground water. A drought can last for months or years, or may be declared after as few as 15 days. It can have a substantial impact on the ecosystem and agriculture of the affected region and harm to the local economy. Annual dry seasons in the tropics significantly increase the chances of a drought developing and subsequent bush fires.Assessment of droughts can be helpful to implement drought mitigation strategies and measures, before they occur again. A wide variety of concepts are applied for drought assessment. In present study, RDI were developed for assessment of the drought for Sabarkantha district. The RDI considers two hydro-meteorological variables (i.e., rainfall and potential evapotranspiration) that affect the droughts. For the assessment of drought, rainfall and PET data of 100 years (i.e., 1901 -2001) were used of Sabarkantha station. For calculating the indices "DrinC" software tool was used. Dry periods were calculated using analysis of RDI-3, RDI-6, RDI-9 and RDI 12 . It is better to use RDI of 12 months' index for analysis of drought for this study.
\end{abstract}

Keywords: Reconnaissance Drought Index (RDI), Rainfall, Potential Evapotranspiration, DrinC.

\section{Introduction}

Drought is a continuous period of dry weather, when an area gets less than its normal amount of rain, over months or even years. Crops and other plants need water to grow, and land animals need it to live. It can become dangerous to people and other animals; A drought is a natural event, caused by other weather events like El Niño and highpressure systems. Drought can also be triggered by deforestation (people cutting down forests), by global warming, and by diverting rivers or emptying lakes.

Drought is a disaster which usually takes place slowly. It is often difficult to decide when a drought started and sometimes when it ends too. Its effects often build up slowly over a long period of time and may last from months to years after rain resumes. Many peopledie every year in famines due to drought in subsistence farming areas. Conflicts can result from drought conditions.

It is not possible to avoid droughts. But drought preparedness can be developed and drought impacts can be managed. In the most general sense, drought originates from a deficiency of precipitation over an extended period of time, usually a season or more, resulting in a water shortagefor some activity, group, or environmental sector Technically, drought is a temporary condition even though it may last for long periods of time.

\section{Drought}

In general, drought means different things to different people. To a meteorologist it is the absence of rain while to the agriculturist it is the deficiency of soil moisture in the crop root zone to support crop growth and hydrologist it is the lowering of water levels in lakes productivity. To the reservoirs, etc., while for the city management it may mean the shortage of drinking wateravailability. Thus, it is unrealistic to expect a universal definition of drought for all fields of activity.

\section{Operational Definition}

An operational definition of drought helps to identify the beginning, end, and degree of severity of a drought. This definition is usually made by comparing the current situation to the historical average, often based on a 30-year period of record. The following categories of drought are usually considered:

Meteorological drought: It is usually defined on the basis of the degree of dryness (in comparison to some normall or average amount) and the duration of the dry period.

Agricultural drought: It links with various characteristics of meteorological or hydrological shortages, differences between actual and potential evapotranspiration, soil water deficits, reduced groundwater or reservoir levels, and so forth.

Hydrological drought: It is associated with the effects of periods of precipitation (including snowfall) shortfalls on surface or subsurface water supply shortage starts to affect people, individually and collectively or, in more abstract terms, most socio economic definitions of drought are associated with the supply and demand of an economic good.

An objective of assessment of drought conditions in a particular region is to plan the water resources in order to prevent and mitigate the occurrence of the drought in further years. In this paper, SPI index was used for assessment of drought 


\section{International Journal of Science and Research (IJSR) \\ ISSN (Online): 2319-7064 \\ Index Copernicus Value (2015): 78.96 | Impact Factor (2015): 6.391}

Malakiya and Suryanarayana(2016) presented the drought analysis. DrinC can be used for the calculation of two indices, the Reconnaissance Drought Index (RDI) \& the Standardized Precipitation Index (SPI).In this study, SPI and RDI were developed for assessment of the drought for Amreli district. The SPI considers rainfall data as only variable, where RDI considers two hydro-meteorological variables (i.e., rainfall and potential evapotranspiration) that affect the droughts. For the assessment of drought, rainfall and PET data of 35 years (i.e., 1965-2000) were used of Amreli station. For calculating the indices "DrinC" software tool was used. Wet and dry period were compared using trend analysis of SPI-3, SPI-6, SPI-9 \& SPI-12 and RDI-3, RDI-6, RDI-9 \& RDI 12. It is better to use SPI and RDI of 12 months' index for analysis of drought for this study. Overall, there was moderate drought situation in Amreli but the duration and intensity was above normal.

Shah et al. (2013) presented conceptual drought and operational drought. The three parameters as the beginning, the end and the degree of severity of the drought can be identifying in operational drought by average precipitation in the whole region. One of the methods classified to measure drought is Reconnaissance Drought Index (RDI). Evapotranspiration is calculated using Penman Monteith method by analyzing thirty nine years prolong climatic data. The evapotranspiration is then utilized in RDI to classify normalized and standardized RDI. These RDI classifications led to what kind of drought faced in Bhavnagar region on 12 month time scale basis. The comparison between actual drought conditionsand RDI method used to find out drought is also illustrated. It can be concluded that the index results of drought in a particular year are same in both methods but having different index values whereas severity remain same.

Drought Identification Indices Drought indices assimilate thousands of bits of data on rainfall, temperature, snowpack, streamflow and other water supply indicators into a comprehensible big picture. A drought index value is typically a single number, far more useful than raw data for decision making. There are several indices that measure how much precipitation for a given period of time has deviated from historically established norms. Although, none of the major indices is inherently superior to the rest in all circumstances, some indices are better suited than others for certain uses. In the international publications different indices have been discussed and applied. Reconnaissance Drought Index (RDI) is one of them.

\section{Reconnaissance Drought Index (RDI)}

The Reconnaissance Drought Index (RDI) can be characterized as a general meteorological index for drought assessment. The RDI can be expressed with three forms: the initial value $\alpha \mathrm{k}$, the normalized RDI (RDIn) and the standardized RDI (RDIst). In this paper we will focus on $\alpha \mathrm{k}$ and RDIst. The initial value $(\alpha \mathrm{k})$ is presented in an aggregated form using a monthly time step and may be calculated on monthly, seasonal (3-month, 4-month, etc.) or annual basis. The $\alpha \mathrm{k}$ for the year $\mathrm{i}$ and a time basis $\mathrm{k}$ (months) is calculated as:
In which Pij and PETij are the precipitation and potential evapotranspiration of the jth month of the ith year and $\mathrm{N}$ is the total number of years of the available data. A second expression, the Normalized RDI (RDIn) is computed using the following equation for each year, in which it is evident that the parameter $\overline{\alpha 0}$ is the arithmetic mean of $\alpha$ o values calculated for the $\mathrm{N}$ years of data

$$
R D I_{n}^{(\mathrm{i})}=\frac{\mathrm{a}_{0}^{(\mathrm{i})}}{\mathbb{\mathrm { a }}_{0}}-1
$$

The third expression, the Standardized RDI (RDIst), is computed following a similar procedure to the one that is used for the calculation of the SPI: The expression for the Standardized RDI is:

$R D I_{n}^{(\mathrm{i})}=\frac{y_{k}^{(\mathrm{i})}-\overline{y_{k}}}{\widehat{\sigma_{y k}}}$

In which yi is the $\ln (\alpha 0(i))$, yk is its arithmetic mean and $\overline{\alpha y} k$ is its standard deviation. The Reconnaissance Drought Index (RDI) was developed to approach the water deficit in a more accurate way, as a sort of balance between input and output in a water system. It is based both on cumulative precipitation $(\mathrm{P})$ and potential evapotranspiration (PET), which are one measured (P) and one calculated (PET) determinant. Positive values of RDIst indicate wet periods, while negative values indicate dry periods compared with the normal conditions of the area. The Table 1 shows the classification of RDI as shown below.

Table 1: Classification of RDI

\begin{tabular}{|c|c|}
\hline Values of RDIst & Description of State \\
\hline-0.5 to -1.0 & Mild \\
\hline-1.0 to -1.5 & Moderate \\
\hline-1.5 to -2.0 & Severe \\
\hline$<-2.0$ & Extreme \\
\hline
\end{tabular}

\section{Study Area \& Data Collection}

SabarkanthaDistrict is bounded by Rajasthan state to the northeast, Banaskantha and Mehsana districts to the west, Gandhinagar to the south and Aravalli District to the South East.The district comprises 7 Talukas. It is spread across an area of $7390 \mathrm{~km}^{2}$. It has a gender ratio of 950 females per 1000 men, and the literacy rate for the district is $76.6 \%$.It falls under sesmic Zone3.For the assessment of drought, rainfall and PET data of 100 years (i.e., 1901 -2001) were used of Sabarkantha station.Fig.1 shows the study area location.

$$
\alpha_{0}^{(i)}=\frac{\sum_{j=1}^{N} P_{i j}}{\sum_{j=1}^{N} P E T_{i j}}
$$




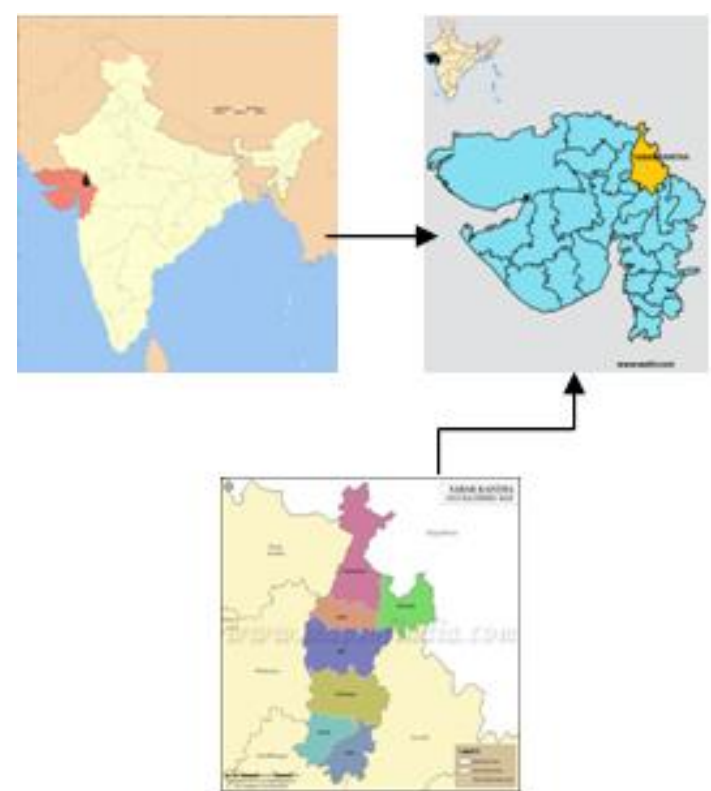

Figure 1: Location of Sabarkantha District

\section{Methodology}

In this study, RDI has been used for assessment of the drought for Sabarkantha district. RDI considers two hydrometeorological variables (i.e., rainfall and potential evapotranspiration) that affect the droughts. For the assessment of drought, precipitation and potential evapotranspiration data for 100 year(1901-2001) of Sabarkantha district was used. Dry periods have been calculated using the RDI- 3, RDI-6, RDI-9, and RDI-12. In this study The Reconnaissance Drought Index (RDI) was calculated using DrinC software. DrinC gives the ability to formulate a drought analysis that suits better the needs or the purpose of this study. The results for each drought index may be presented per period that allows a direct comparison of drought severity for specific periods of the year.

\section{Results and Analysis}

\section{For RDI 3,}

For Sabarkantha district, Fig. 2 shows the value of RDI 3 for 100 years. It indicates the severity of drought. Table 2 gives that severe drought was observed 9 times and extreme drought was observed 4 times. Table 2 also indicates that extreme drought was not observed after 1950-51 and last severe drought was noticed in 1994-95, considering the years 1901-2001.

Table 2: Severe \& extreme drought years considering RDI

\begin{tabular}{|c|c|c|c|c|}
\hline \multirow{2}{*}{ RDI 3 3} & \multicolumn{2}{|c|}{ Severe } & \multicolumn{2}{c|}{ Extreme } \\
\cline { 2 - 5 } & Year & Time Interval & Year & Time Interval \\
\hline & $1905-06$ & - & $1907-08$ & - \\
\hline & $19021-22$ & 16 & $1920-21$ & 13 \\
\hline & $1939-40$ & 18 & $1945-46$ & 25 \\
\hline & $1953-54$ & 14 & $1950-51$ & 5 \\
\hline & $1968-69$ & 15 & & \\
\hline & $1972-73$ & 4 & & \\
\hline & $1984-85$ & 12 & & \\
\hline & $1989-90$ & 5 & & \\
\hline & $1994-95$ & 5 & & \\
\hline
\end{tabular}

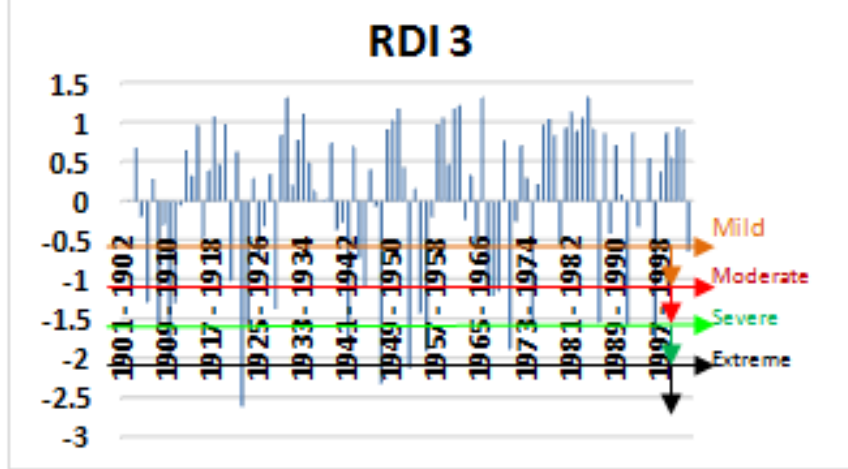

Figure 2: Plot of RDI 3 for period 1901-2001

\section{For RDI 6,}

For Sabarkantha district, Fig. 3 shows the value of RDI 6 for 100 years. Table 3 gives that severe drought was observed only once and extreme drought was observed 7 times. Table 3 also indicates that extreme drought was not observed after 1984-85, considering the years 1901-2001.

Table 3: Severe \& extreme drought years considering RDI 6

\begin{tabular}{|l|c|l|c|l|}
\hline \multirow{2}{*}{ RDI6 } & \multicolumn{2}{|c|}{ Severe } & \multicolumn{2}{c|}{ Extreme } \\
\cline { 2 - 5 } & Year & Time Interval & Year & Time Interval \\
\hline & $1966-67$ & - & $1903-04$ & - \\
\hline & & & $1918-19$ & 15 \\
\hline & & & $1921-22$ & 3 \\
\hline & & & $1950-51$ & 29 \\
\hline & & & $1953-54$ & 3 \\
\hline & & & $1964-65$ & 11 \\
\hline & & & $1984-85$ & 20 \\
\hline
\end{tabular}

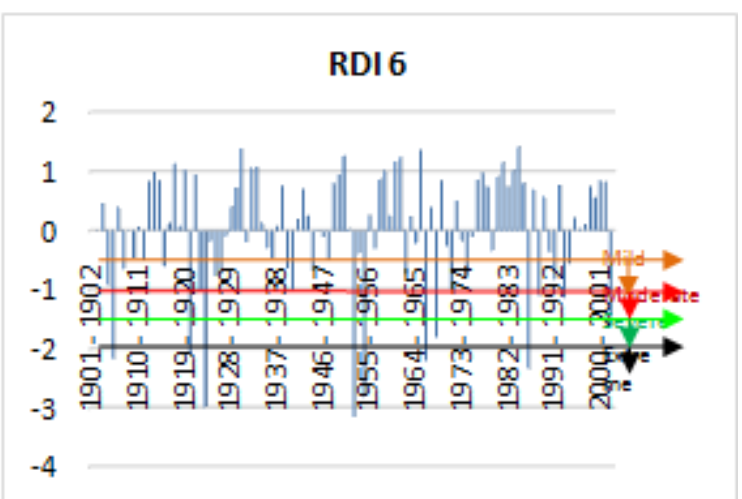

Figure 3: Plot of RDI 6 for period 1901-2001

\section{For RDI 9,}

For Sabarkantha district, Fig. 4 shows the value of RDI 9for 100 years. Table 4 severe drought was observed 2 times and extreme drought was observed 3 times. Table 4 indicates that extreme drought was not observed after 1984-85 and last severe drought was noticed in 1941-42, considering the years 1901-2001. 


\section{International Journal of Science and Research (IJSR) ISSN (Online): 2319-7064}

Index Copernicus Value (2015): 78.96 | Impact Factor (2015): 6.391

Table 4: Severe \& extreme drought years considering RDI 9

\begin{tabular}{|c|c|c|c|c|}
\hline \multirow{2}{*}{ RDI 9 } & \multicolumn{2}{|c|}{ Severe } & \multicolumn{2}{c|}{ Extreme } \\
\cline { 2 - 5 } & Year & Time Interval & Year & Time Interval \\
\hline & $1939-40$ & - & $1950-51$ & - \\
\hline & $1941-42$ & 2 & $1968-69$ & 18 \\
\hline & & & $1984-85$ & 16 \\
\hline
\end{tabular}

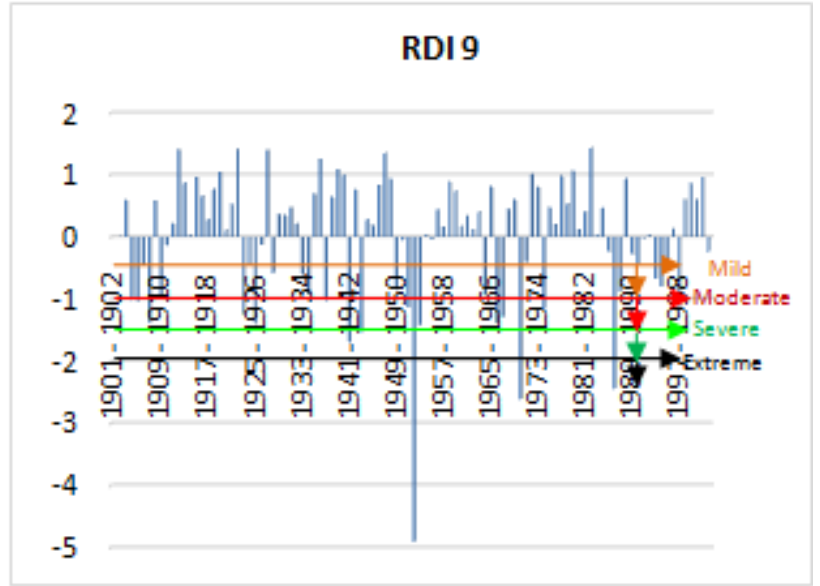

Figure 4: Plot of RDI 9 for period 1901-2001

\section{For RDI 12,}

For Sabarkantha district, Fig. 5 shows the value of RDI 12 for 100 years. Table 5 severe drought was observed 3 times and extreme drought observed 6 times. Table 5 also indicates that extreme drought was not observed after 198788 and last severe drought was noticed in 1969-70, considering the years 1901-2001.

Table 5: Severe \& extreme drought years considering RDI

\begin{tabular}{|c|c|c|c|c|}
\hline \multirow{3}{*}{ RDI 12 } & \multicolumn{2}{|c|}{ Severe } & \multicolumn{2}{c|}{ Extreme } \\
\cline { 2 - 5 } & Year & Time Interval & year & Time Interval \\
\hline & $1948-49$ & - & $1904-05$ & - \\
\hline & $1951-52$ & 3 & $1911-12$ & 7 \\
\hline & $1969-70$ & 18 & $1915-16$ & 4 \\
\hline & & & $1923-24$ & 8 \\
\hline & & & $1974-75$ & 51 \\
\hline & & & $1987-88$ & 13 \\
\hline
\end{tabular}

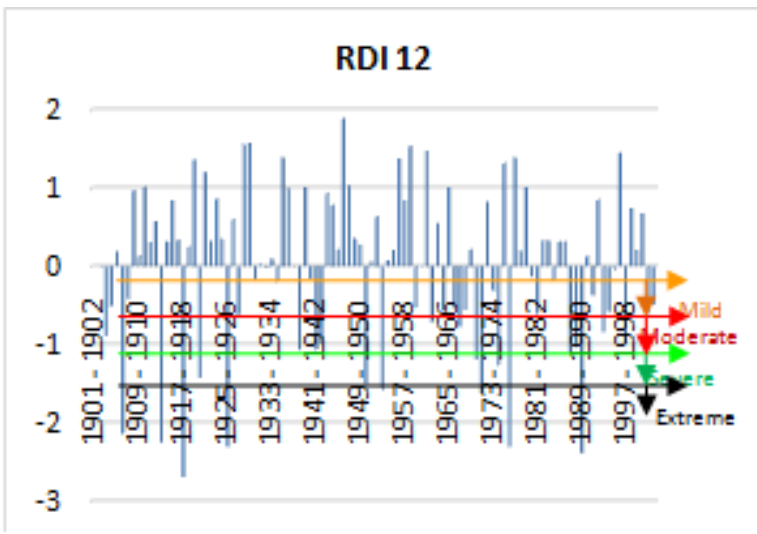

Figure 5: Plot of RDI 12 for period 1901-2001

Fig. 6, Fig.7, Fig.8 and Fig. 9 shows the trend analysis of RDI 3, RDI 6, RDI 9 and RDI 12 respectively.

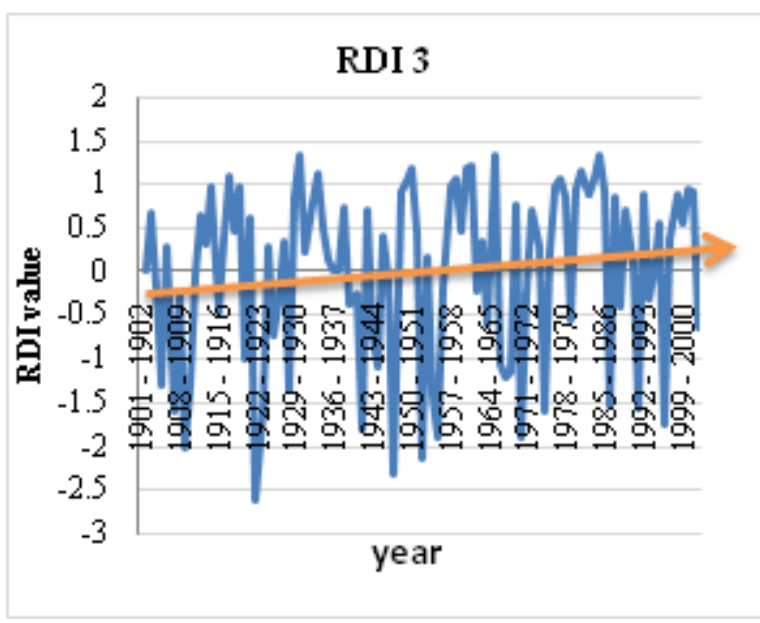

Figure 6: Trend of RDI 3

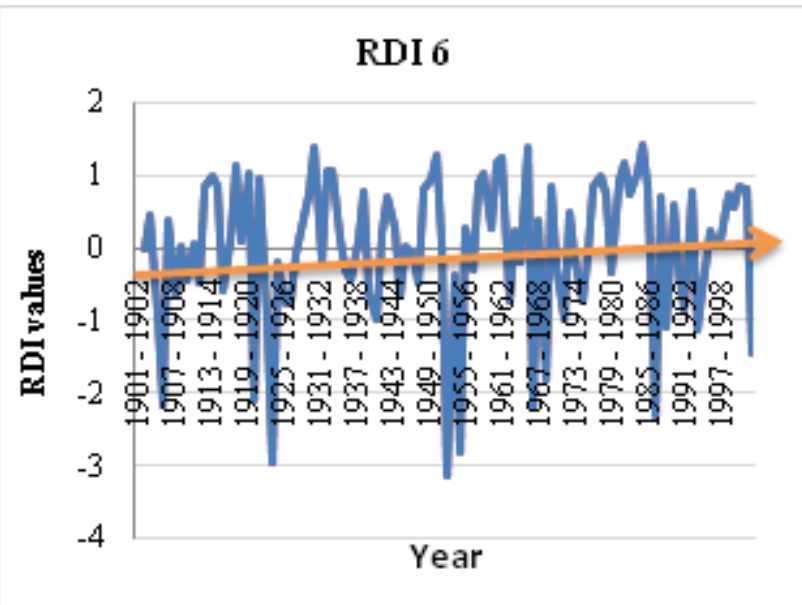

Figure 7: Trend of RDI 6

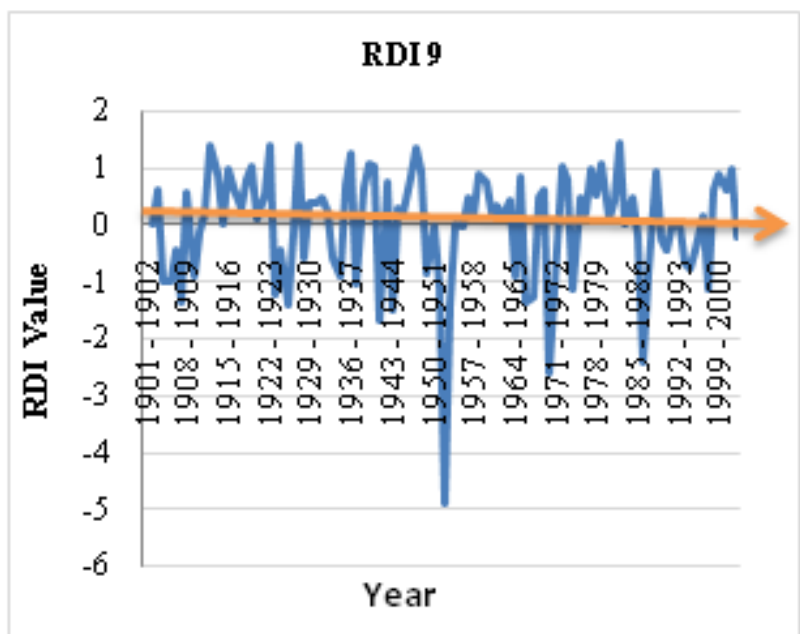

Figure 8: Trend of RDI 9 
International Journal of Science and Research (IJSR)

ISSN (Online): 2319-7064

Index Copernicus Value (2015): 78.96 | Impact Factor (2015): 6.391

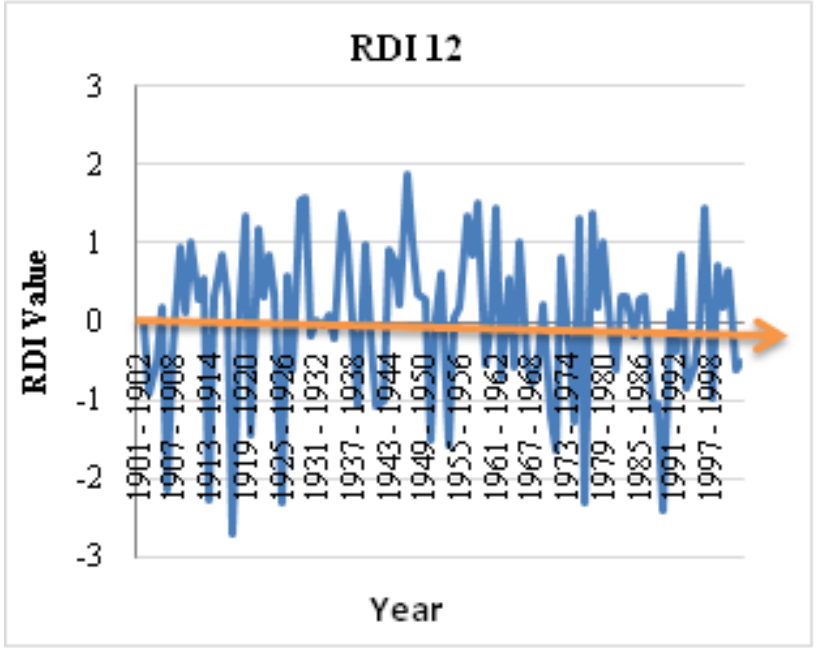

Figure 9: Trend of RDI 12

\section{Conclusions}

The frequency of drought events was calculated using the Reconnaissance Drought Index (RDI) and it is used to detect the changes in severity of drought in Sabarkantha district.

As per RDI 3, it is observed that severe drought has occurred 9 times in 100 years and it comes probably once in 12-15 years. Extreme drought has occurred 3 times in 100 years and lastly it was observed in 1950-51.

As per RDI 6, severe drought was observed once in 1966-67. The extreme drought was observed 7 times in 100 years.

As per RDI 9, severe drought was observed 2 times and extreme drought was observed 3 times in 100 years.

As per RDI 12, severe drought was observed 3 times and extreme drought was observed 6 times in 100 years.

As per the study of overall trend of RDI, the decline of drought line is observed, which indicates the possible increase in occurrences of drought.

\section{References}

[1] Malakiya, A.D. and Suryanarayana, T.M.V. (2016) "Assessment of Drought Using Standardized Precipitation Index (SPI) and Reconnaissance Drought Index (RDI): A Case Study of Amreli District"International Journal of Science and Research (IJSR)Volume 5 Issue 8, August 2016.

[2] Shah, R., Manekar, V. L., Christian, R. A. and Mistry, N. J. (2013) "Estimation of Reconnaissance Drought Index (RDI) for Bhavnagar District, Gujarat, India International Journal of Environmental, Chemical, Ecological, Geological and Geophysical Engineering" Vol:7, No:7, 2013

\section{Author Profile}

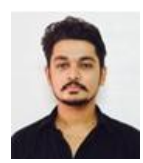

Nikhil Lunagaria received the B.E. Degree in Civil Engineering from V.V.P. College of Engineering Technology, Rajkot in 2015 and is currently pursuing
M.E. (Civil)Water Resources Engineering from Water Resources Engineering and Management Institute, Faculty of Technology and Engineering, The Maharaja Sayajirao University of Baroda.Resources Engineering from Water Resources Engineering and Management Institute, Faculty of Technology and Engineering, The Maharaja Sayajirao University of Baroda.

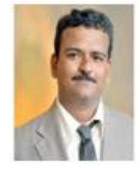

Dr. T.M.V. Suryanarayana is born in Visakhapatnam on 11th February, 1979 and completed B.E.(Civil- IWM) in May 2001, M.E.(Civil) in Water Resources Engineering in November 2002 and Ph.D. in Civil Engineering in May 2007 from The Maharaja Sayajirao University of Baroda, Vadodara, Gujarat, India. He is serving as Associate Professor \& recognized Ph.D. Guide in Water Resources Engineering and Management Institute, Faculty of Technology \& Engineering, The Maharaja Sayajirao University of Baroda. He has 14.50 years of teaching and Research Experience. His areas of research include Operations Research, Hydrologic Modeling, Conjunctive Use, Hydraulics of Sediment Transport, Soil and Water Conservation, Reservoir Operation, Soft Computing Techniques, Climate Change. He has been invited for delivering Expert Lectures at Various National Level Institutes and also as a speaker on programmes related to Awareness on Water Management. He has obtained Three Best Paper Awards at different National level conferences and Two Best Poster Awards at different National Level Events. He has under his credit around 98 Research Papers published in various International / National Journals / Seminars / Conferences / Symposiums. 